\title{
Exploring the Factors that Hinder Jordanian Students in Developing Creativity in EFL Writing
}

\author{
Luqman Mahmoud Rababah, Mohammad Hamza Alshehab, and Nour Zakaria Bani Melhem
}

\begin{abstract}
Although Jordan has made great efforts to develop students' EFL writing skills in general and creativity in writing in particular, studies revealed that Jordanian students still had problems with creativity in writing. However, few studies have been conducted on creativity in EFL writing. Therefore, this study investigated the barriers that hinder student's creativity in EFL writing. This qualitative study involved EFL secondary stage students in Jordan. Eight EFL male students were selected with the help of convenience sampling. The findings show that low-scoring EFL students' responses could be categorized into three themes, namely, inadequate vocabulary, lack of unity and coherence and lack of support. The study contributes to the literature concerning creativity in EFL writing in the context of Jordan and in the Arab region. Jordanian educators need to consider the constraining factors of creativity such as lack of vocabulary in order to enhance students' creativity in writing.
\end{abstract}

Keywords- Creativity, Constraining Factors, Discovery Schools (DSs), EFL writing Jordan, TTCT

\section{INTRODUCTION}

In a constant effort to foster 21st-century literacies, the Jordanian Ministry of Education (JMoE) has become a strong advocate of student enhancement of such literacies. The ministry has launched several ventures such as the Jordan Education Initiative (JEI) (2003), Education Reform for Knowledge Economy (ERfKE) (2003), Connecting Jordanians' Initiative (2005) and English Interactive Online Initiative (EIOI) (2006), aiming to enhance students ' creativity and develop English Language skills [1]

The educational system in Jordan is based on the notions of freedom, justice, and human and economic development in an attempt to achieve a considerable degree of productivity and progress [2]. The Jordanian educational system stresses the significance of lifelong learning experiences so that students meet present and future needs and stimulate sustained economic development through an educated population and social and economic development.

Luqman Mahmoud Rababah, College of Arts and Languages, Jadara University, Jordan, Email: Rababah80@ gmail.com

Mohammad Hamza Alshehab, College of Arts and Languages, Jadara University, Jordan, Email: Jordan_1948@yahoo.com

Nour Zakaria Bani Melhem, Department of English Language, Majmaah University, Saudi Arabia, Email: prettyshatha@yahoo.com
Accordingly, the Jordanian educational system encourages excellence, stresses learners' needs, allows universal access to educational opportunities, facilitates equality in the provision of services, promotes the use of modern ICT tools, and offers the best teaching and learning strategies and methods to promote student success [3].

However, despite the best efforts expended by the JMoE in developing creativity in EFL writing, Ibnain [4] and Rababah and Melhem [1] studies revealed that Jordanian secondary school students still had problems with creativity in EFL English. However, the current study contributes to the literature concerning creativity in EFL writing in the context of Jordan and in the Arab region. Moreover, the current study has adopted a full qualitative research design to get an in-depth and clear picture in a natural setting. Finally, exploring the barriers that students face while developing their creativity in EFL writing could also help curricula designers and EFL methodologists understand students' difficulties in the creativity process and help in developing strategies to overcome these barriers in the future. The purpose of the current study is to answer the research question entitled "What are the constraining factors that hinder students' creativity in EFL writing?" to determine the constraining factors that they encountered in EFL writing creativity.

\section{LITERATURE REVIEW}

Both researchers and educators have looked into barriers to EFL student creativity in writing. These include whether educationalists and policy makers included creativity as an objective and whether students face obstacles [5], [6]. Teachers play a crucial role in either fostering or hindering learners ${ }^{6}$ creative potential [7].

Research revealed that students barriers to writing abilities could be attributed to several factors, First, students may have a poor attitude about their writing abilities and/or attitudes from previous writing failure experiences [8]. Second, students are unmotivated to use the writing process and lack a clear cognitive awareness of the purpose of the writing process [9]. Third, reluctant writers experience difficulties due to spelling and handwriting problems, poor mechanical skill, a lack of lexical structure or a fear of exposing their feelings. Fourth, inadequate teacher training and reliance on ineffective past practices, daily time constraints, and a lack of immediate and positive feedback 
may create problems. Fifth, many teachers may insist that writing be accomplished in a silent, non-interactive environment.

\section{Methodology}

The study has used qualitative approach to draw conclusions on the barriers that student face in Jordan. The eight participants of the study were mainly secondary school students drawn from Amman cities in Jordan. A convenience sample of the secondary schools students was selected for the study. However, the participants have studied English language skills for about eleven years. They speak Arabic language as their mother tongue. This study employed the semi-structured interview strategy because according to several researchers who claim the advantages of semi-structured interviews and its superiority over other kinds [10]. To check the trustworthiness and credibility of qualitative data, the researcher utilized member check, which is an invaluable method in establishing credibility of findings [10], [11]. To uphold the confidentiality of participants, the researcher identified them only by codes. The responses of the interviewees were changed into a coded system in the following way; teacher $\mathrm{X}$ - for instance (SA) refers to -Student A.

\section{RESULTS AND DISCUSSION}

To examine the barriers that the students face while promoting their creativity in EFL writing and to determine the answer to the third research question, which required interviewing students.

Based on the findings of the students' creative writing level, $66 \%$ of the students were categorized in the moderate level of creativity, $16 \%$ were in the low level and $18 \%$ were in the high level. The findings for the level of students in EFL writing creativity, analyzed through SPSS version 17 are shown in Table1.

TABLE 1.TTCT Results of Students' Creativity Level in EFL Writing (N=50)

\begin{tabular}{lccc}
\hline Scale of Creativity & Score & F & $\%$ \\
\hline High level & 25 and above & 9 & $18 \%$ \\
Moderate level & From 13-24 & 33 & $66 \%$ \\
Low level & 12 and below & 8 & $16 \%$ \\
\hline
\end{tabular}

Based on the TTCT results, only eight students fell into the low level of creativity, and they were the ones who were interviewed to determine the answer to the third question. The eight students provided their feedback concerning the constraining factors that they experienced while developing their EFL writing creativity. Their responses revealed three themes, namely, inadequate vocabulary, lack of unity and coherence, and lack of support. The following paragraphs provide the qualitative analysis of their responses.

\section{A. The First Theme: Inadequate Vocabulary}

The students' responses from the interviews revealed inadequate vocabulary as the first theme. The students highlighted this theme as one of the barriers that blocked their
EFL writing creativity. Among eight of the students who scored low on creativity (TTCT), five stated that they possessed low vocabulary, and some of their responses are provided in the following paragraphs; To begin with, SD stated that "among the primary obstacles that I faced stems from my limited vocabulary, as I was unable to express the ideas that I had.... I am a good Arabic writer but poor in English composition owing to this broken English on account of my low scope of vocabulary.... It is evident that more vocabulary could improve the writing skills of students" (SD, Interview, November 21, 2012). Vocabulary scope is a primary element of writing skills. The majority of the low-performing students were convinced that a link existed between vocabulary scope and writing abilities. Specifically, SB stated, - I believe that lack of vocabulary could impact the writing quality, and it is a main constraining factor that could hinder writing abilities\| (SB, Interview, November 8, 2012). According to participants, employing a strategy that encourages students to use vocabulary in actual situations might positively impact writing quality. SA stated that "teachers may adopt some strategies or remedial materials which could help enhance and maximize vocabulary particularly for those who did not do well in TTCT" (SA, Interview, November 5, 2012).

The students highlighted this theme as one of the barriers that blocked their EFL writing creativity. Five stated that they possessed low vocabulary. In learning the English Language, the lexis or vocabulary is recognized as a vital factor for ESL development [12]. Chomsky [13]stated, "Once students have mastered a language, the class of sentences with which students can operate fluently and without difficulty or hesitation is so vast for all practical purposes and, obviously, for all theoretical purposes" (p. 426). Amabile [14] considered knowledge to be one of the components of creativity that allows people to build the technical expertise that can serve as a foundation for creativity within a given domain. In the current study, student SD stated that, among the primary obstacles that he faced, was his limited vocabulary as he was unable to express the ideas that he had. The fluency component is the ability to make ideas by means of words, but if the words are missing, creativity will be blocked [15]. A person characterized as lacking in creativity will merely manage limited ideas, which in turn, will confine his/her planning process and lead to an incomplete or limited writing process. Research has shown the relationships between creativity and the vocabulary level [16], [17]. Salem [18] also said that second/foreign learners faced difficulties writing effectively because of a limited vocabulary.

\section{B. The Second Theme: Lack of Unity and Coherence}

The inability to write texts in a coherent and cohesive way is the second theme obtained from the students ' interviews. Three of the participating students claimed that they were unable to stick to the topic of the essay, as they had no idea how to proceed (e.g., SG, Interview, November 26, 2012). Another student, SF, claimed that I am not familiar with the rule of coherence and is unaware of the expressions and phrases used to keep the smooth flow of the speech ... the teacher used to advise 
me to keep the consistency of pronouns in the paragraph as I shifts from one pronoun to another, owing to my lack of knowledge concerning writing rules (SF, Interview, November20, 2012). Similarly, SC reported -my problem lies in how to construct sentences in order and how to shift from one sentence to another and how to link between sentences so that they become meaningful\| (SC, Interview, November 6, 2012). It is evident from the above that students faced unity and coherence problems, the skills of which are very crucial in writing skills. Their lack of rules familiarity limited their writing abilities.

The inability to write texts in a coherent and cohesive way was the second theme obtained from the students ' interviews. Three of the participating students claimed that they were unable to stick to the topic of the essay because they had no idea how to do so (e.g., SG).

Both Chomsky and Vygotsky discussed the issues of coherence and cohesion. Referring to linguistic factors, Chomsky [13] stated that discourse was not a series of random utterances but fit the situation that evokes it. People impose interpretations on that discourse in which it is assumed to be relevant, coherent, and appropriate. Vygotsky [19] asserted that language, thinking and therefore learning are intimately tied together. Teaching the students how to make the sense of a sentence may increase their fluency and the generation of ideas. Linguistic factors refer to the basic language skills involved in assembling words into meaningful sequences. However, coherence is not just assembling a series of words. Coherence is achieved when a piece of writing is easy to understand because its parts are connected in a clear and reasonable way and the piece forms a unified whole. While the concept of cohesion is a semantic one; it refers to relations of meaning that exist within the text, and that define it as a text. Previous studies have found that linguistic factors are crucial in enhancing writing abilities and, if they are lacking, creativity may be blocked [20]-[22].

Flower and Hayes's [15] writing model includes the concept of organizing, which involves choosing the subject matter that the generating process has created and structuring that subject matter into writing. The process includes structuring information in a cohesive and coherent manner through knowledge derived from long-term memory and the task environment [15]. In doing so, ideas are put into language (text generation) and then, in turn, into written words (transcription) to build a cohesive and coherent text.

\section{The Third Theme: Lack of support}

On the basis of the interview results, seven students said a lack of support was a barrier to their writing abilities. According to these students, they needed their teachers' support to keep on writing. Specifically, SH stated "English teachers do not provide students with the opportunity to express themselves.... Teachers sometimes criticize us for not knowing how to write in a proper way" (SH, Interview, November 28, 2012). Another student SF claimed, "During writing classes, I often feel frustrated for being neglected by the teacher.... The teacher focuses on good students and even though I have broken
English. I deserve the teachers' consideration, concentration and encouragement" (SF, Interview, November 20, 2012). Because of this perceived ill treatment, SF started to hate the English language. He said: "Low-performing students often feel frustrated when neglected by the teacher. More often than not, teachers concentrate on good students. Students having low proficiency in English should be attended to and encouraged by teachers so that they won't start hating the subject" (SF, Interview, November 20, 2012).

Other students claimed that they required help and support to continue writing, particularly with respect to relevant topics. According to SE, "teachers often come up with topics that are irrelevant to the students' needs, concerns and experiences and this discourages students from writing about the topic. Consequently, students will refuse to write about it for lack of knowledge" (SE, Interview, November 15, 2012). Similarly, SG commented "he is not encouraged to ask questions and explore ideas by teachers, and, thus, he remained quiet during class discussions for the fear of being embarrassed or failing" (SG, Interview, November 26, 2012). Many students participating in the interview said that their teachers did not give them any sort of extrinsic motivation to keep them motivated to write.

Some students reported not receiving any positive feedback. They said that they required positive feedback to continue writing. Below are some of their comments; SB reported that Teachers concentrate more on grammar and mechanics and what they might not realize is that criticizing the students on this light may discourage them from attempting to construct complex structures and using new vocabulary in writing (SB, Interview, November 8, 2012). The students stressed the importance of positive feedback from teachers. SD stated that, -Feedback can be beneficial to students.... Teachers should provide feedback in such a way that the students will want to try harder\| (SD, Interview, December 21, 2012). Students reported that the lack of support via feedback diminished motivation and created a discouraging environment.

On the basis of interview results, seven students whose creativity was rated as low noted lack of support as a barrier to their writing abilities. For example, SH stated, -English teachers do not provide students with the opportunity to express themselves\|. SG (Interview, November 26, 2012) commented - he is not encouraged to ask questions and explore ideas by teachers and thus, he remains quiet during class discussions for the fear of being embarrassed or failing\|. Support includes, among other things, directly teaching and the scaffolding of information for students[23].

Another component developing creativity is the social environment. The social environment includes all of the extrinsic motivators that have been shown to undermine intrinsic motivation, as well as a number of other factors in the environment that can serve either as obstacles or as stimulants to the motivation of learning. Indeed, many theorists have seen motivation as the single most important component of creativity. Krashen [24] said that a student with low motivation, self-confidence and high anxiety, would have a higher affective filter that did not provide the learner with - subconscious 
language acquisition. Amabile (1996) stressed that motivation was essential for creative performance and has the power to propel a person in the pursuit of unachieved goals throughout the creative process.

Motivation is a kind of support that students need to enhance their creativity [25]. Learners need encouragement and support whether from teachers or peer students. To encourage learners to find and solve problems in ways that facilitate original ideas, students need tools to communicate novel thinking to enhance their learning. Students' motivation could also be external, which means that attributes of the environment, such as grades, rewards or social acceptance, encourage them to learn. Inspiring creativity in writing is not difficult to achieve in an EFL classroom, as the teachers just need to encourage the students to write and communicate [26]. Nickerson [27] argued that a balanced environment, both demanding and supportive, is necessary for creativity to flourish. Lavoie [28] argued that a student who was fearful of being embarrassed would go to great lengths to avoid that task.

Some students in this study reported not receiving any positive feedback. They said that they required positive feedback to continue writing. Student SB reported that his teacher criticized the students in a negative way and that discouraged him from attempting to construct complex structures and use new vocabulary in writing. To achieve the best results, feedback should be both timely and appropriate [29]. Research has revealed several environmental factors that can block creativity, such as a norm that harshly criticizes new ideas [30], [25]. Assessment feedback provides an ideal opportunity for teachers to encourage students in their risk-taking and the novel expressions of ideas, as well as sharing information on how students could improve or adapt their ideas for a different context [27]. Evidence has suggested that students who perceive their teachers as being caring, accepting, interested in them, courteous, and professional, are more likely to express their creativity [31]. As Fasko [32] explained, when students believe that their teachers - value\| creativity, the message of value has a positive effect on creativity. Previous research has proven the importance of motivation, feedback and encouragement on enhancing high-order thinking [33]-[35]. A number of studies have indicated that interacting with the learning environment influences creative behaviour [35], [36].

The most significant part of the study is the implications of the findings concerning creativity in EFL writing instruction in Jordan, specifically in DSs. The hope is that the information in this section will guide future instructors as they attempt to enhance their students' creativity in writing. Teachers, along with program directors or program leaders, should make an effort to overcome the barriers students face. One of the most important berries is the lack of vocabulary. Lack of adequate vocabulary knowledge is an obvious and serious obstacle for some students, and their numbers can be expected to rise as an increasing proportion of them fall into categories considered educationally at risk. Increasing vocabulary knowledge is a basic part of the process of education, both as a means and as an end. At the same time, advances in knowledge will create an ever-larger pool of concepts and words that a person must master to be creative writer. The findings of this study support the need for quality vocabulary instruction in schools as a means of increasing students" word knowledge for enhancing their vocabularies. At the very least, it is paramount that educators at every level become sensitive to the issues surrounding vocabulary knowledge and learning. As a starting point, teachers need to be aware of the many benefits of vocabulary instruction for their students if they are ever to take on the task of incorporating rich instruction into their practice in writing. It is believed that if teachers are aware, specifically those who deal with students from lower socio economic backgrounds, they will be up to the challenge of providing the rich instruction for their students.

Additionally, exploring the barriers that students face in developing creativity in EFL writing could also help curricula designers and EFL methodologists in understanding students' difficulties in the creativity process. This understanding would help teachers in breaking down barriers and encouraging them to use more suitable methods in the future. One more barrier is the lack for unity and coherence among eight students.

Both educators and teachers could follow Lee's [37] method to teach coherence in writing courses. Lee taught each of the five aspects of coherence following five stages of instruction: 1) Introductory activities: In this stage, Lee asks the participants questions that draw students' attention to the importance of the introduced aspect in writing. To introduce Macrostructure, she asks students to narrate a story or to describe, for example, an embarrassing event that happened to them and to analyze its structure. 2) Explicit teaching: Lee supplies explanations of the meaning of the introduced aspect and of its role in achieving coherence. She does this through simple-text analyses or by asking students to edit sentences or passages applying the instructions provided in the lecture. 3) Student handouts: In the handouts, the introduced aspect is explained with examples which illustrate its use. They are meant to be kept as a reference of the lectures. 4) Awareness-raising tasks: In this stage, students analyze texts in which there are problems of incoherence and try to edit them following the instructions they received on the concerned aspect(s). They can reorder an ill organized passage to realize a given macro-pattern or complete one which lacks a necessary feature of coherence. 5) Writing practice: This is the stage in which students try to apply what they have learned in the previous stages to their own productions. Students are given a topic and asked to plan their compositions following, for example, a given macro-pattern. What is crucial about this method is that all the aspects of coherence are given equal importance and are defined using precise terms. However, the results of this study should be spread across the educational field for more effective professional development because teachers need information to support their classroom practices while EFL students require more effective writing practices that deviate from the traditional way of teaching. 
The present study is just an initial step, but the hope is that it can raise awareness about engendering creativity in EFL writing instruction in DSs as well as in other schools across the nation. As a result of this study, several recommendations may be made for future research to reduce the knowledge gap. Future studies that focus on the barriers that students face in developing their writing creativity should be more in-depth. The barriers should be further explored and ways of minimising the impact of these barriers on the creativity in writing should be examined.

\section{REFERENCES}

[1] L. Rababah and N. B. Melhem, "Investigation into Strategies of Creativity in EFL Writing in Jordan," J. Lit. Lang. Linguist., vol. 3, no. 5, pp. 14-25, 2015.

[2] M. M. H. Drbseh, "The spread of English language in Jordan," Int. J. Sci. Res. Publ., vol. 3, no. 9, 2013.

[3] F. Al-Adwan, "The national strategy for career guidance at the Ministry of Education," Minist. Educ. Amman, Jordan, 2009.

[4] S. S. K. Ibnian, "Brainstorming and essay writing in EFL class," Theory Pract. Lang. Stud., vol. 1, no. 3, pp. 263-272, 2011. https://doi.org/10.4304/tpls.1.3.263-272

[5] R. Cachia, A. Ferrari, K. Ala-Mutka, Y. Punie, and others, "Creative learning and innovative teaching: Final report on the study on creativity and innovation in education in EU member states," 2010.

[6] J. L. Rinkevich, "Creative teaching: Why it matters and where to begin," Clear. House A J. Educ. Strateg. Issues Ideas, vol. 84, no. 5, pp. 219-223, 2011. https://doi.org/10.1080/00098655.2011.575416

[7] D. Wyse and D. Spendlove, "Partners in creativity: action research and creative partnerships," Educ. 3--13, vol. 35, no. 2, pp. 181-191, 2007.

[8] L. Buhrke, L. Henkels, J. Klene, and H. Pfister, "Improving Fourth Grade Students' Writing Skills and Attitudes.," 2002.

[9] T. J. Cumberworth and J. A. Hunt, "Improving Middle School Student Writing Skills and Attitudes toward Writing.," 1998.

[10] J. W. Creswell, Research design: Qualitative, quantitative, and mixed methods approaches. Sage publications, 2013.

[11] M. Denscombe, The good research guide: for small-scale social research projects. McGraw-Hill Education (UK), 2014.

[12] S. A. Stahl, "Four problems with teaching word meanings," Teach. Learn. Vocab. Bringing Res. to Pract., pp. 95-114, 2005.

[13] N. Chomsky, "A note on the creative aspect of language use," Philos. Rev., vol. 91, no. 3, pp. 423-434, 1982. https://doi.org/10.2307/2184692

[14] B. A. Hennessey and T. M. Amabile, "Creativity.," Annu. Rev. Psychol., vol. 61, pp. 569-598, 2010. https://doi.org/10.1146/annurev.psych.093008.100416

[15] L. Flower and J. R. Hayes, "A cognitive process theory of writing," Coll. Compos. Commun., vol. 32, no. 4, pp. 365-387, 1981. https://doi.org/10.2307/356600

[16] M. Fahim and A. Komijani, "Critical thinking ability," L2 Vocab. knowledge, L2 Vocab. Learn., 2010.

[17] F. Seddigh and N. Shokrpour, "Creativity and its relationship with vocabulary learning strategy use of EFL students," J. Stud. Educ., vol. 3, no. 2, pp. 139-151, 2013. https://doi.org/10.5296/jse.v3i2.3199

[18] M. S. A.-S. Salem, "The effect of journal writing on written performance, writing apprehension, and attitudes of Egyptian English majors," The Pennsylvania State University, 2007.

[19] L. Vygotsky, "Interaction between learning and development," Readings Dev. Child., vol. 23, no. 3, pp. 34-41, 1978.

[20] M. M. Grosser and M. Nel, "The relationship between the critical thinking skills and the academic language proficiency of prospective teachers," South African J. Educ., vol. 33, no. 2, pp. 1-17, 2013. https://doi.org/10.15700/saje.v33n2a639

[21] B. Ghonsooly and S. Showqi, "The effects of foreign language learning on creativity," English Lang. Teach., vol. 5, no. 4, p. 161, 2012. https://doi.org/10.5539/elt.v5n4p161

[22] A. V Kharkhurin, "The role of cross-linguistic and cross-cultural experiences in bilinguals' divergent thinking," in Cognitive aspects of bilingualism, Springer, 2007, pp. 175-210.

[23] W. R. Adams, Think, read, react, plan, write, rewrite. Holt, Rinehart and Winston, 1986.

[24] S. Krashen, "The input hypothesis and its rivals," Implicit Explic. Learn. Lang., pp. 45-77, 1994.

[25] Joy, "Innovation motivation: The need to be different," Creat. Res. J., vol. 16, no. 2-3, pp. 313-330, 2004. https://doi.org/10.1080/10400419.2004.9651461

[26] R. S. Al-Jarf, "Online instruction and creative writing by Saudi EFL freshman students," King Saud Univ. Saudi Arab. Available http//www. asian-efl journal. com/pta_Aug_07_rajl.php, 2007.

[27] R. S. Nickerson, "20 Enhancing Creativity," Handb. Creat., p. 392, 1999.

[28] R. Lavoie, The motivation breakthrough: 6 secrets to turning on the tuned-out child. Simon and Schuster, 2008.

[29] G. Hunt, D. G. Wiseman, and T. J. Touzel, Effective teaching: preparation and implementation. Charles C Thomas Publisher, 2009.

[30] T. M. Amabile, "Creativity and innovation in organizations," Harvard Bus. Sch., vol. 5, pp. 1-15, 1996.

[31] E. Tighe, M. L. Picariello, and T. M. Amabile, "Environmental influences on motivation and creativity in the classroom," Educ. Psychol. Creat., pp. 199-222, 2003.

[32] D. Fasko, "Education and creativity," Creat. Res. J., vol. 13, no. 3-4, pp. 317-327, 2001. https://doi.org/10.1207/S15326934CRJ1334_09

[33] D. S. Stein, C. E. Wanstreet, P. Slagle, L. A. Trinko, and M. Lutz, "From 'hello'to higher-order thinking: The effect of coaching and feedback on online chats," Internet High. Educ., vol. 16, pp. 78-84, 2013. https://doi.org/10.1016/j.iheduc.2012.03.001

[34] J. H. Kaufman and C. D. Schunn, "Students' perceptions about peer assessment for writing: their origin and impact on revision work," Instr. Sci., vol. 39, no. 3, pp. 387-406, 2011. https://doi.org/10.1007/s11251-010-9133-6

[35] J. C. Kaufman and R. J. Sternberg, The Cambridge handbook of creativity. Cambridge University Press, 2010. https://doi.org/10.1017/CBO9780511763205

[36] E. Z.-F. Liu, L. I. N. Chun-Hung, J. Pei-Hsin, and L. Pey-Yan, "The dynamics of motivation and learning strategy in a creativity-supporting learning environment in higher education," TOJET Turkish Online J. Educ. Technol., vol. 11, no. 1, 2012.

[37] S. Lee, "Teaching EFL writing in the university: Related issues, insights, and implications," J. Natl. Taipei Teach. Coll., vol. 16, no. 1, pp. 111-136, 2003.

Luqman Rababah, $\mathrm{PhD}$, is an Assistant Professor of Applied Linguistics within the School of English Language \& Translation, Jadara University, Jordan, where he teaches courses on Sociolinguistics, Pragmatics and Second Language Acquisition theories. He has more than ten publications. His research is concentrated in two areas: Second Language Acquisition theories, and Writing. The best paper award and a certificate were given for one of his research paper entitled "The level of creativity in English writing among Jordanian secondary school students" which was presented at the $2^{\text {nd }}$ International Conference on Arts, Social Sciences \& Technology Penang, Malaysia 2012. There were more than 300 hundred participants in the conference.

Dr. Rababah received his PhD in Applied Linguistics from the Northern University of Malaysia, Malaysia (2015). He holds a bachelor's degree in English Language from Yarmouk University, Jordan (2003). He holds higher diploma and master's degrees in Teaching English as a Second or Other Languages (TESOL) from Amman University, Jordan in 2005 and 2006 respectively. He previously taught courses in applied linguistics, language development, and sociolinguistics at Majmaa University, Saudi Arabia. His teaching career also includes extensive experience in teaching English as a second (ESL) and foreign language (EFL) to learners of various levels of proficiency. Dr. Rababah's research has been published in various journals,including JALT, Applied Linguistics, TESOL Quarterly, and the CALICO Journal. 